\title{
Solid State Transformers: An Emerging Trend in Power Quality Improvement
}

\author{
Saju $\mathbf{N}^{1}$, Dr. Jegathesan $\mathbf{V}^{2}$, Aiswarya K $\mathbf{P}^{3}$ \\ ${ }^{1}$ Research Scholar, Karunya Institute of Technology and Sciences, Coimbatore, India, \\ ${ }^{2}$ Associate ${ }^{2}$ Professor, Karunya University, Coimbatore, India. \\ ${ }^{3} P G$ Scholar, NSS College of Engineering, Palakkad, India.
}

\begin{abstract}
To have a comprehensive review on the different SST topologies and analyses its application suitability. Presently different topologies of SST exist. Each topology has its own relative advantages which makes it suitable for specific applications. An analysis of the different topologies and its merits making it suitable for different areas of application is discussed in detail. A simulation of A Single Stage and a Three Stage SST topology are simulated in MATLAB and the results are discussed in this paper. The review clearly evolves the relative merits of SST over conventional transformers, the losses and efficiencies of SST seems to be very much acceptable in comparison to a conventional transformer. The advantages of various topologies namely Matrix type, Isolated back- end type, Isolated front- end type, Isolated modular multilevel converter and single cell makes its suitable for applications in AC dual active bridge, Traction, Electric Vehicles, Renewable Energy Sources. These topologies are less complex and offer high flexibility. SST has the main feature of reduced size, weight and volume, high power density, higher efficiency, fault isolation, reactive power compensation and improved power factor which makes it adaptable for various applications.
\end{abstract}

Keywords: DC/DC converter, fast charging of EV, FACTS, distribution system, power quality, Solid State Transformer(SST).

\section{INTRODUCTION}

Transformers are critical elements of the power distribution system and are less expensive, highly reliable and efficient ${ }^{[1]}$. However, they own a few risks consisting of voltage drop under load, protection from system disruptions and overload, sensitivity to harmonics, system protection from problems arising at or beyond the transformer, environmental concerns concerning mineral oil, and performance beneath dc offset load unbalances. These disadvantages are gaining more importance as power quality becomes more of a concern ${ }^{[1]}$. The solid state transformer becomes a suitable option to replace the conventional copper and iron based transformer for a better power quality with the advancement of power electronic devices and circuits. The solid state switching technologies provide power conversion between different formats such as DC/DC, AC/DC, DC/AC and AC/AC with any desired frequencies.

Now days, a lot of renewable electricity sources is constantly developing so that it will reduce the emission of greenhouse gas and replace the confined strength resources like coal, oil or uranium. This has given upward push to a large number of distributed power plants, which are principally subject to great-electricity fluctuations. With the intention to improve power quality through harmonic filtering, voltage sag and swell mitigation, reactive power compensation and high dynamic control of real and reactive power flow and to easily connect the new energy sources to grid new power electronic systems called intelligent universal transformers called solid state transformers are required. These interconnected devices would replace voluminous and heavy line frequency transformers. Based on such devices a smart grid comparable to the internet where distributed energy uploads and downloads, a plug and play connection of sources and loads and energy routing for transferring energy from the producer to the consumer is viable.

An ordinary power system has three main components, namely generation, transmission and distribution. Each component is characterized by a specific voltage level based on its function $^{[2]}$. This makes it necessary to transform the electrical power from one voltage level to another. This is possible by means of a transformer, making them an essential structural element of power system. The research in transformer technology is directed mainly towards development of new magnetic, conducting and insulating materials in order to reduce losses and to match the required transformer rating. Deregulation of power generation is being considered as a viable option to meet the increasing power demands in the past few decades ${ }^{[2]}$.

This deregulation has resulted in an increased usage of distributed energy resources (DER) in the distribution system which is now causing power quality issues. The harmonics introduced in power system by DERs are posing challenges for transformer design. DER integration also causes problems of over-voltage or under-voltage under many circumstances. There are limitations on both - the voltage control margin and 
the frequency of operation of the tap changers, even though the use of tap-changers enables the transformer to control the terminal voltage. ${ }^{[2]}$

In the past few decades, power electronics has emerged as a promising solution to deal with the problems of complex power systems. The high power and controllable solid state switches have triggered development of various power electronic converters which can be used in both transmission and distribution systems. The use of FACTS converters for maintaining power quality in distribution network is gaining popularity ${ }^{[2]}$. The benefit of using smart transformer is the ability to realize energy savings by setting the voltage of electricity provided to the minimum level required for running various appliances. ${ }^{[18]}$ In the near future, electricity grids will integrate large scale renewable sources such as photovoltaic (PV) and wind farms. The intermittent nature of energy generation from such sources creates many challenges to the electricity grid. Advanced intelligent and smart transformers will be needed to achieve proper operation of the future grids besides enhancing power quality and securing energy supply to critical loads ${ }^{[18]}$.Solid state transformers would also enable power consumers to switch electricity sources depending on the current price of electricity. Consumers could buy power from others having excess power in the same neighborhoodthereby leading to a more distributed nature of the electric grid.

\section{SOLID STATE TRANSFORMER}

The term solid state transformer is not a transformer in the traditional sense. It is a collection of conventional high frequency transformers, high powered semiconductor components, and control circuitry which is used to provide a huge level of flexible control of power distribution networks. Due to add some communication capability, the entire package is often referred to as a smart transformer. In the recent years, another high power converter, named solid-state transformer (SST) (also known as power electronic transformer or intelligent universal transformer), has caught much attention.

Over the past few years, several efforts have been taken to deliver a low-voltage and power using SST prototype ${ }^{[8]}$. However, SSTs at the present time are limited by voltage and power rating of the power devices, and have not penetrated into the distribution systems as such. ${ }^{[8]}$ The main idea of the SST is to achieve the voltage transformation by medium- to high-frequency isolation, thereby to potentially reduce the weight, size and volume of it compared with the traditional power transformer. ${ }^{[8]} \mathrm{A} 50 \mathrm{~Hz}$ ac voltage is transformed to a high frequency one (normally in the range of several kilohertz to tens of kilohertz), then this high-frequency voltage is stepped up/down by a high frequency transformer with significantly decreased weight, size and volume and finally, shaped back into the desired $50 \mathrm{~Hz}$ voltage to feed the load. ${ }^{[8]}$

SST has some other potential functionality that are not owned by the traditional transformer. At first, the use of solid-state semiconductor devices and circuits makes the voltage and current regulation a possibility; similarly to FACTs devices.
This brings promising advantages such as real and reactive power flow control, voltage sag and swell mitigation, reactive power compensation, fault current limitation, and others, which are not possible for traditional transformers. Second, voltage source converters connected from the secondary terminal of the SST could readily support a regulated dc bus, which could be connected to dc micro grids enabling this new micro grid architecture.

The primary purpose is to reduce the size, weight and volume to improve efficiency dramatically. Solid state transformers can potentially offer significant benefits compared to traditional transformers- such as bidirectional power flow, high efficiency, superior power quality, high flexibility and lower maintenance costs.

In renewable energy areas, solid state transformers would allow DC power to be transmitted to the grid without the need for equipment currently being used for power conversion and thereby to reduce voltage fluctuations. Solid state transformers would also enable power consumers to switch electricity sources depending on the current price of electricity. Consumers could buy power from others having excess power in the same neighborhood- thereby leading to a more distributed nature of the electric grid. ${ }^{[18]}$ Future electricity grids will integrate large scale renewable sources such as photovoltaic (PV) and wind farms. SST is an element consists of multi stage power electronic converters with high frequency transformer, proposed in National Science Foundation (NSF) Generation III Engineering Research Centre (ERC) "Future Electric Energy Delivery and Management (FREEDM) Systems" which was established in 2008 and the proposal of SST was regarded as one of the most emerging technologies by Massachusetts Institute of Technology (MIT) Technology review in 2010. These transformers must be able to provide intelligent power management as well as subsidiary services $^{[18]}$. The efficient supply on the selection of suitable voltage levels for different sections of the energy distribution system was thus adopted.

When higher levels of power are required, a medium- voltage levels in the tens of kilovolts range is typically selected. In accordance to current trends in energy conversion, the supply of power must fulfill several functionality requirements among which high power quality access to a low- voltage DC interface can be highlighted. Moreover, low energy losses, high power density, low failure rate and total cost of ownership remains as major research challenges. Solid state transformers comply with these functionality requirements as well as with the demanded high performance levels while directly connecting to medium- voltage.

\section{BASIC TOPOLOGIES IN SOLID STATE TRANSFORMER}

There are a number of topologies for the power electronic converters of SST which enable it to provide additional functionalities. ${ }^{[2]}$ The SST topologies can be widely classified into three categories - single-stage, two-stage and three-stage. A modular approach is adapted to operate SST with solid state 
switches of available ratings. The main aim of this section is only to introduce three basic bidirectional topologies ${ }^{[2]}$.

\section{a) Single-Stage Topology}

The single-stage SST topology consists of an AC/AC full bridge converter. It converts the low frequency $\mathrm{AC}$ input to a high-frequency output which is then stepped down using a high-frequency transformer. The output of HF transformer is further converted to power frequency using another converter. The major disadvantage of the topology is the absence of a DC link which limits the functionality of SST. ${ }^{[2]}$

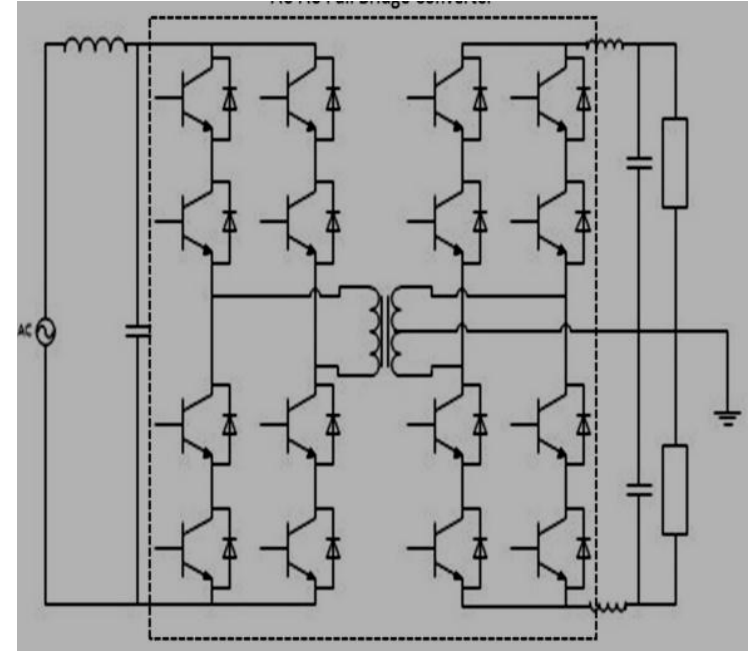

Fig.1. Single Stage SST Topology

\section{b) Two - Stage Topology}

It consists of two two-stage topologies. The two-stage topology uses an AC/DC dual active bridge with a PWM inverter. The SST with two stage topology avails a LVDC link which can be used for integration of DERs ${ }^{[2]}$. This topology results in higher efficiency with zero voltage switching strategy. However, this type of converter suffers from the problem of high sensitivity of active power flow on leakage inductance and high ripple current. Another two-stage topology replaces the AC/DC dual active bridge with an $\mathrm{AC} / \mathrm{DC}$ isolated boost converter ${ }^{[2]}$.

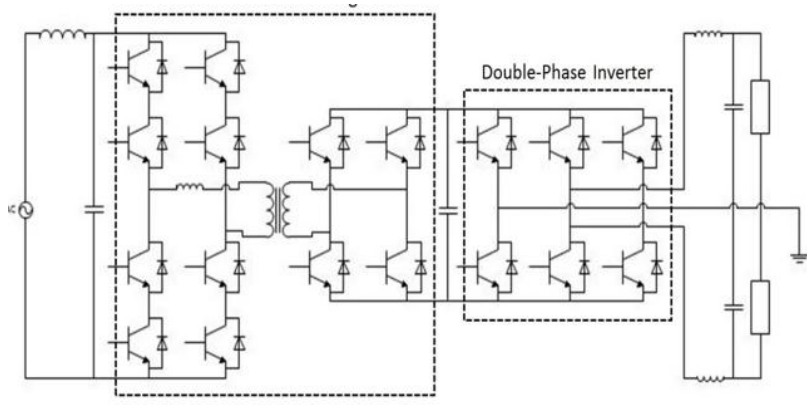

Fig.2. Two Stage SST Topology

\section{c) Three - Stage Topology}

${ }^{[2]}$ It consists of a PWM rectifier, DC/DC dual active bridge and a PWM inverter. This topology requires switching between two alternative control schemes for power flow in either direction. Since, the three stage topology involves an HVDC interlink, the voltage rating constraints of solid-state switching devices become significant and it is mandatory to use multilevel converters for rectification.

It mainly consists of three stages- input stage, isolation stage and an output stage which is shown in Fig.4. ${ }^{[2]}$

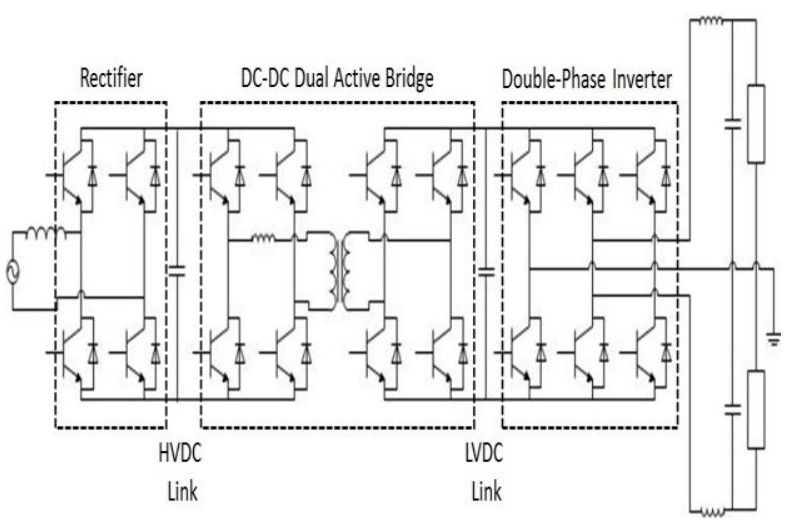

Fig.3. Three Stage SST Topology

The main topology discussed here is single stage topology because of reduced number of stages, cost and complexity. ${ }^{[2]}$

\section{A. Converter topologies}

SST has various topologies. ${ }^{[20]}$ Some of the five topologies are:
i) Matrix type
ii) Isolated back- end type
iii) Isolated front- end type
iv) Isolated modular multilevel converter and single cell approach.

Matrix type topology: It is suitable for AC dual active bridge applications. Such topology offers flexibility, low complexity and is used where volume and weight are key constraints. ${ }^{\text {[20] }}$

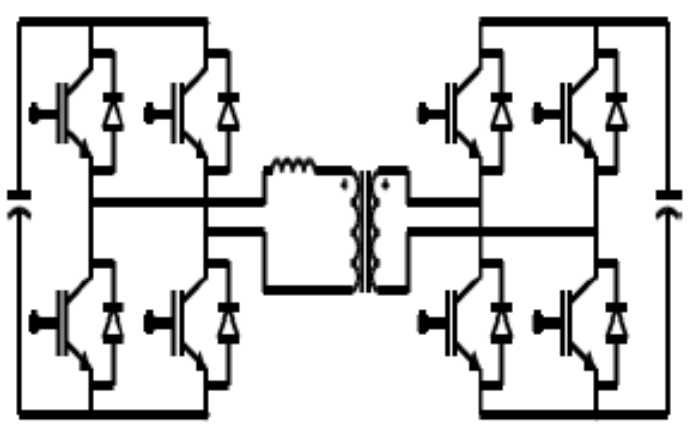

Fig.4. DAB Based Solid State Transformer

A DAB based solid state transformer is shown in Fig.5. It has symmetric configuration and energy storage capability. Such topology is used in airborne applications and power quality improvement techniques. ${ }^{[20]}$

\section{Isolated back- end type}

These are used for AC/AC and AC/DC applications with less complexity. It can be used in traction systems, electric vehicles, etc ${ }^{[20]}$. 


\section{Isolated front- end type}

It is used in high power applications like interconnection of renewable energy systems.

\section{Isolated modular multilevel converter and single cell} approach

It is very easy and simple to control and does not need individual de supplies. ${ }^{[20]}$

\section{B. Stages of a solid state transformer}

It mainly contains three stages- input stage, isolation stage and output stage. In the input stage, there is a converter, which converts the input $\mathrm{AC}$ voltage to $\mathrm{DC}$ voltage, i.e., rectifier. The second part of the converter is formed by a DC/AC converter. This part of the converter contains the high frequency transformer with the high insulation capability. In the output part, the medium frequency voltage is revealed as a power-frequency voltage. Here, a three part design is introduced. It is a new configuration based on the matrix converter with new function. It can provide desired output AC voltage $^{[7]}$. In addition, it performs power quality improvement functions, such as sag correction, reactive power compensation, fault isolation and is capable of providing three-phase power from a single phase system. The SST has three stages and each stage can be controlled independently from the other one by proper mechanisms. Many advantages of the SST such as output power quality and power factor correction depend on appropriate close-loop control, and correlative research techniques. The reliability of a system is indirectly proportional to the number of components used in SST. The main purpose of proposed SST is reduction in the power delivery stage (AC/DC and DC/AC links) in SST with an intermediate DC-link. ${ }^{[7]}$

1) Input Stage: The input stage is a three phase or single phase PWM rectifier, which is used to convert the primary low frequency voltage into the low frequency DC voltage. The main functions associated with the rectifier control are shaping the input current, reactive power compensation, controlling the input power factor, and keeping the DC-link voltage at the desired reference value. Many control methods are presented for control of input stage in conventional SST, which could be used in proposed SSTshows three phase rectifier with input inductances ${ }^{[7]}$.To realize constant DC voltage and keep input current sinusoidal, the double control loops, a DC voltage outer loop and an AC current inner loop, are adopted. The reference for the active current is derived from the DC voltage outer loop. The reference for the reactive current is set to zero to get unity power factor. The current error signals are input the current regulators and then form the modulation signals. The basic structure of input stage is shown in Fig.6. ${ }^{[7]}$

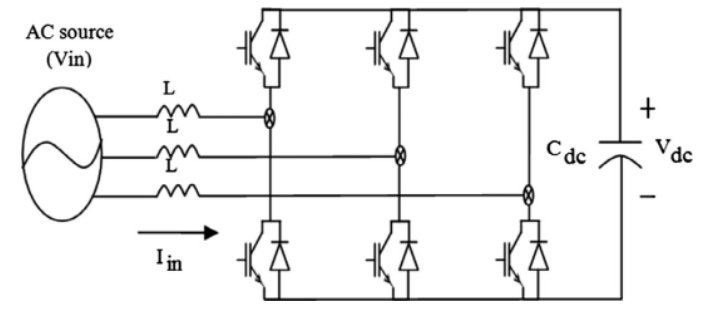

Fig.5. Structure of Input Stage
2) Isolation Stage: It contains a single phase high frequency voltage source converter or bridge converter, which converts the input high voltage DC to low voltage output DC. It uses a high frequency transformer (two winding). The main functions of transformers are voltage transformation and isolation between source and the load. To simplify the design, open loop control is applied. The principle or modulation used here is PWM method. It mainly uses a Dual Active Bridge (DAB) topology. The main functions of the MF transformer are such as voltage transformation and isolation between source and load. Circuit diagram of VSC is the same as that of an H-bridge topology. To simplify the design of the control system, open loop control is applied for the VSC. The principle of modulation is based on the comparison of a sinusoidal reference waveformwith zero carrier waveform ${ }^{[7]}$. The principle of switching $\mathrm{H}$-bridge is described with conditions below:

Condition 1: if sin wave $>0$, then $\mathrm{H} 1$ and $\mathrm{H} 2$ are turned-on.

Condition 2: if sin wave $<0$, then $\mathrm{H} 3$ and $\mathrm{H} 4$ are turned on.

If sine reference wave has a frequency $f_{r}$ and an amplitude $A_{r}$ then output voltage of VSC has a frequency $f_{r}$. By neglecting the losses of MF transformer, the MF transformer can be treated as a proportional amplifier. ${ }^{[7]}$

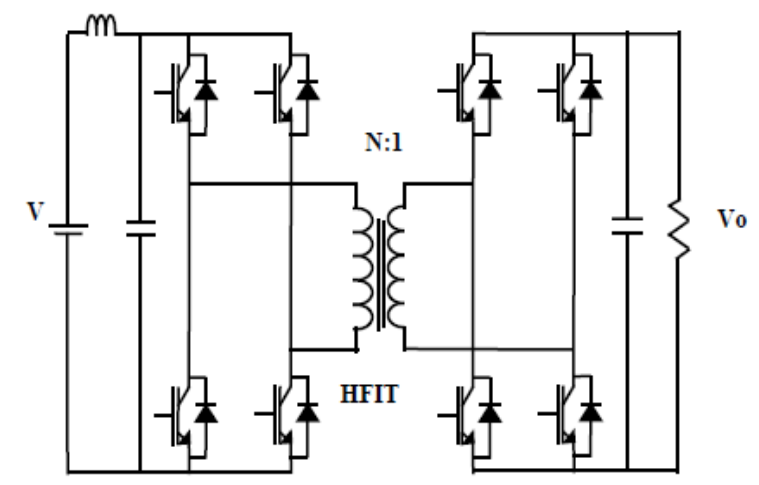

Fig.6. DAB Topology in Isolation stage of SST

3) Output Stage: This stage uses matrix conversion topology. It converts low voltage DC produced by isolation stage to low voltage $\mathrm{AC}^{[7]}$. After that this low voltage $\mathrm{AC}$ is passed through an output LC filter and then to the load. The common emitter anti-parallel IGBT with diode pair arrangement is used in this topology. The proposed converter generates desired output voltage with suitable shape and frequency. Several modulation schemes have been proposed for traditional inverters. Among those the most commonly used is SPWM (Sinusiodal PWM) or SVPWM (Space Vector PWM). ${ }^{[7]}$

\section{SOLID STATE TRANSFORMER IN POWER GRID FOR POWER QUALITY IMPROVEMENT}

Generally, we are using traditional power transformers in grid for stepping up/down voltages. But there are some shortcomings for these power transformers as it doesnot compensate voltage sag and swell, reactive power, fault isolation, etc..we can overcome these drawbacks by using SST. SST performs the following functionalities: 
1) Voltage sag and swell compensation: One of the most important features of SST is voltage sag or swell ride through capability. It is done in the rectifier stage and will not affect the load side voltage. The maximum input current determines how much voltage sag the SST can compensate. The maximum input voltage determines how much voltage swell an SST can support. When the voltage sag is so large, the dc bus capacitance will determine how many cycles the SST can compensate.

2) Reactive power compensation: It is done by the rectifier stage. Depending on the reactive power reference, SST can generate or absorb rated reactive power to the grid. This helps to increase voltage support, reduce transmission line losses and improve transmission line stability.

3) Fault isolation: SST will stay online but limit the load current to two times of the rated current. Then some of the electronic equipment loads are not affected and still able to operate under a low voltage. After the circuit breaker or fuse trip the fault, the SST will again output rated voltage. This is the protection scheme for short circuit.

4) Black start capability: With the interconnection of DRERs and DESDs to the SST, the smart grid is capable of operating in an islanded state. The amount of load capable of being restored is dependent on the total amount of DRER and DESD connected to the SST. This must be regulated by the Distributed Grid Intelligence ${ }^{[25]}$. The grid connected and islanded operations of SST require separate control methods. When grid connection is there, SST supplies the load and the PV cell charges the battery bank. When grid connection is lost, the Distributed Grid Intelligence creates an islanded state ${ }^{[25]}$. During this time SST changes its state and starts black start operation. When power generated by PV is zero, then DESD must discharge. When power generated by PV cell is more than that of load, then DESD must absorb the excess generation. When power generated by PV is less than that of load, then both DRER and DESD must discharge.

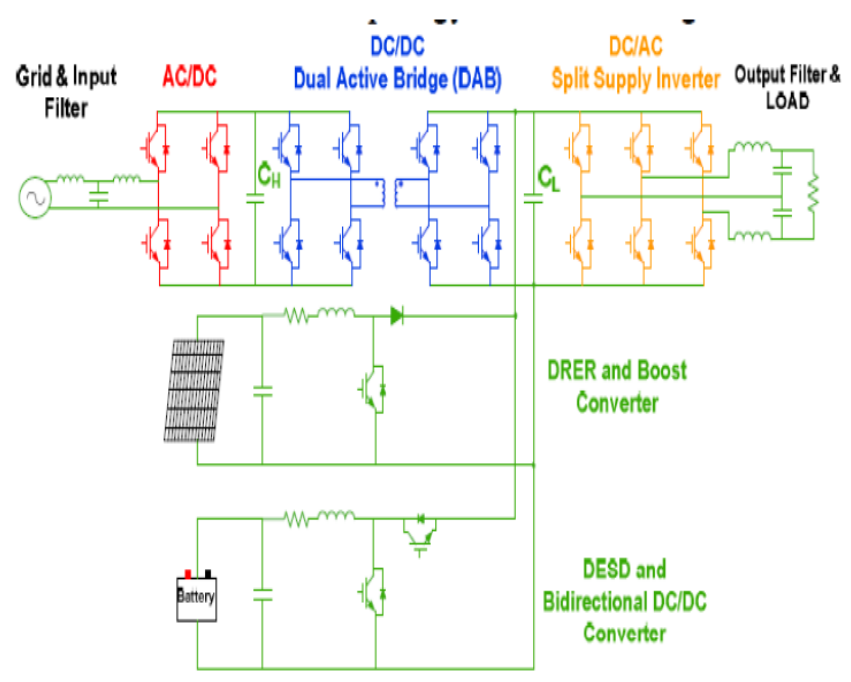

Fig.7. SST in Power grid

\section{APPLICATIONS OF THE PROPOSED TRANSFORMER IN POWER QUALITY}

SST can be used in many areas where traditional/conventional transformers are used. SST has many applications in different areas. The use of SST instead of power transformers depends upon the advantages of SST. Due to reduced size, weight and volume, high power density, higher efficiency, fault isolation, reactive power compensation and improved power factor, SSTs are mostly preferred. It has additional features of black start capability. More application areas are:

1) PWM drives

2) Traction application

3) Dc charging station

4) FACTS

5) Micro grids

6) Integration of renewable energy resources

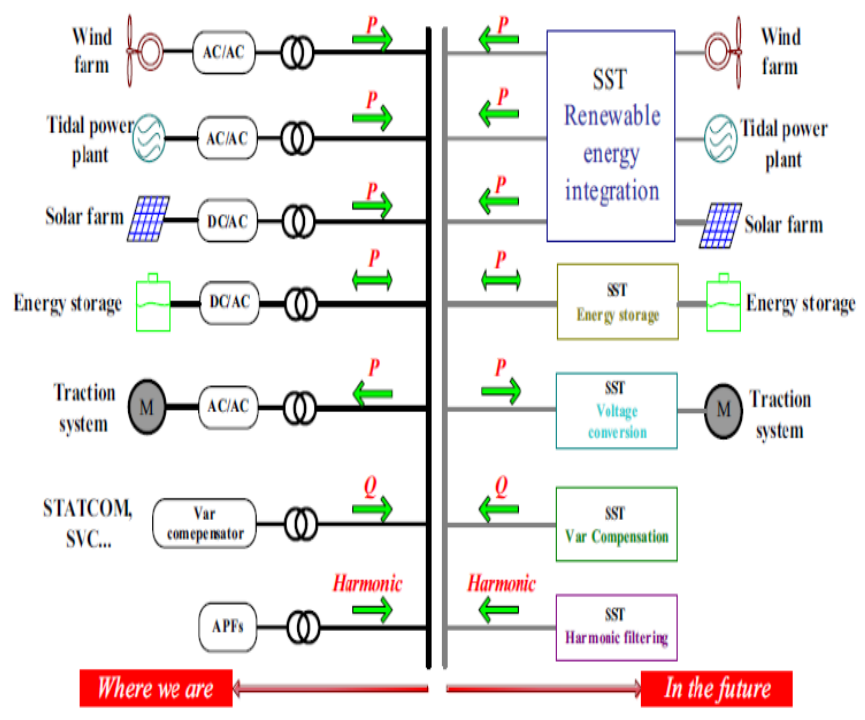

Fig.8. Application areas of SST

A) Wind Power Integration

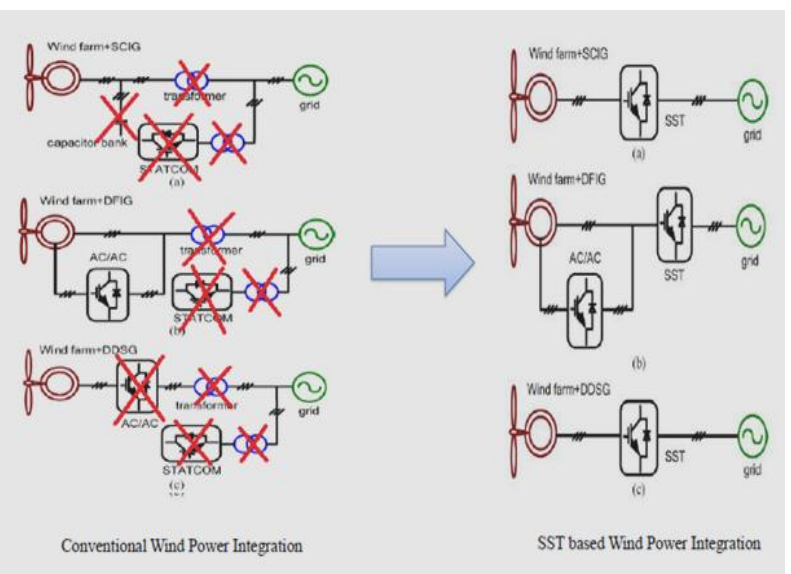

Fig.9. Application of SST in Renewable Energy Integration 
Table 1.Comparison of Conventional Transformer and Solid State Transformer in Wind Power Integration

\begin{tabular}{|l|l|}
\hline $\begin{array}{l}\text { Conventional Wind Power } \\
\text { Integration }\end{array}$ & $\begin{array}{l}\text { SST based Wind Power } \\
\text { Integration }\end{array}$ \\
\hline $\begin{array}{l}\text { Requires large number of } \\
\text { power electronic devices like } \\
\text { transformers, STATCOMs, } \\
\text { converters, etc... }\end{array}$ & $\begin{array}{l}\text { All the devices are replaced } \\
\text { with a single unit -SST }\end{array}$ \\
\hline Less power density & High power density \\
\hline $\begin{array}{l}\text { Overall size is increased and } \\
\text { have huge weight and volume }\end{array}$ & $\begin{array}{l}\text { Less size, weight and } \\
\text { volume }\end{array}$ \\
\hline High cost & Less cost \\
\hline
\end{tabular}

\section{B) Traction Application}

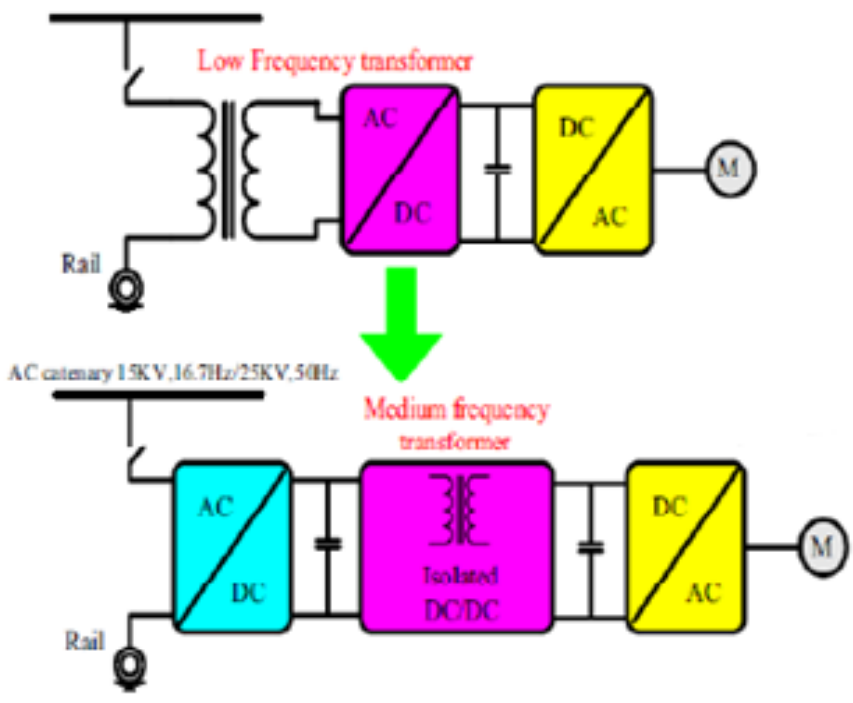

Fig.10. Application of SST in Traction area

Table 2. Comparison of Conventional Transformer and Solid State Transformer In Traction Application

\begin{tabular}{|l|l|}
\hline $\begin{array}{l}\text { Conventional Traction } \\
\text { Application }\end{array}$ & $\begin{array}{l}\text { SST based Traction } \\
\text { Application }\end{array}$ \\
\hline Efficiency: about $88 \%-92 \%$ & Efficiency: about $95 \%$ \\
\hline Less power density & High power density \\
\hline $\begin{array}{l}\text { Overall size is increased and } \\
\text { have huge weight and volume }\end{array}$ & Less size, weight and volume \\
\hline High cost & Less cost \\
\hline Less power quality & $\begin{array}{l}\text { High power quality due to } \\
\text { the properties of SST }\end{array}$ \\
\hline
\end{tabular}

C) DC Charge Station

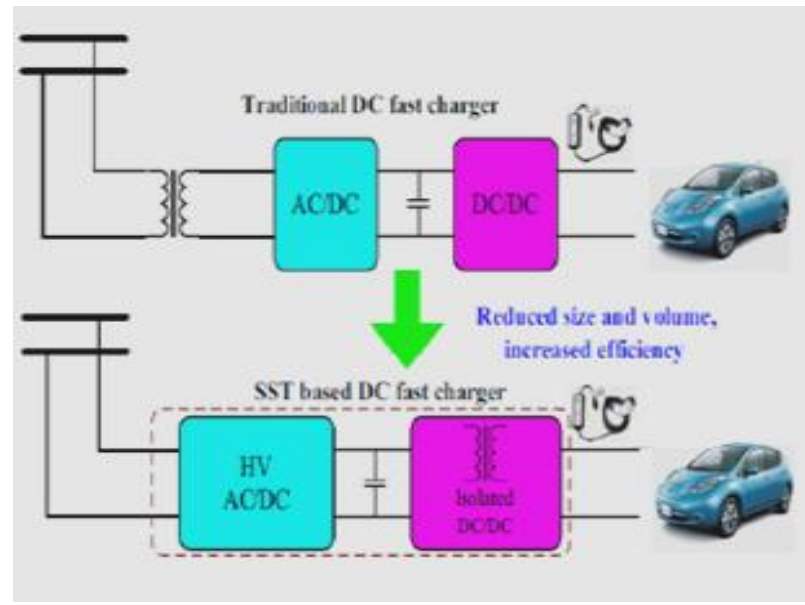

Fig.11. Application of SST in DC Charge Station

Table 3.Comparison of Conventional Transformer And Solid State Transformer In DC Charge Station

\begin{tabular}{|l|l|}
\hline $\begin{array}{l}\text { Conventional Transformers } \\
\text { in DC Charge Station }\end{array}$ & $\begin{array}{l}\text { SST based DC Charge } \\
\text { Station }\end{array}$ \\
\hline Efficiency: about 90\% & Efficiency: about 95\% \\
\hline Less power density & High power density \\
\hline $\begin{array}{l}\text { Overall size is increased and } \\
\text { have huge weight and volume }\end{array}$ & Less size, weight and volume \\
\hline High cost & $\begin{array}{l}\text { Cost is reduced to half of that } \\
\text { by using conventional } \\
\text { transformer }\end{array}$ \\
\hline Less power quality & $\begin{array}{l}\text { High power quality due to } \\
\text { the properties of SST }\end{array}$ \\
\hline
\end{tabular}

In future, SST can replace all the conventional power transformers due to its advantages.

\section{SIMULATION OF THE PROPOSED SYSTEM}

In order to ensure the feasibility of the system simulation is carried through pulse width modulation method for threestage and single- stage SST. And by comparing these two results it has observed that single- stage SSTs has key advantages such as
i. Higher efficiency
ii. Black start capability
iii. Voltage drop under load is eliminated
iv. Not sensitive to harmonics
v. Reduced size, weight and volume
vi. High power density
vii. Real and reactive power control
viii. Power factor improvement
ix. Voltage sag and swell compensation
x. Protection from system disruptions and overloads
xi. Transmission line stability
xii. Improved power quality 
International Journal of Engineering Research and Technology. ISSN 0974-3154, Volume 13, Number 5 (2020), pp. 900-908

(C) International Research Publication House. https://dx.doi.org/10.37624/IJERT/13.5.2020.900-908

Simulation parameters are shown in table 4.1 and table 4.2 simulation circuit diagrams is shown in Fig 12 and Fig 14.

Table 4.1 Simulation Parameters for Three stage SST

\begin{tabular}{|l|l|}
\hline Input voltage & $415 \mathrm{~V}$ \\
\hline Output voltage & $90 \mathrm{~V}$ \\
\hline Duty ratio & 0.8 \\
\hline Switching frequency & $1 \mathrm{KHz}$ \\
\hline Array peak power & $1 \mathrm{KW}$ \\
\hline
\end{tabular}

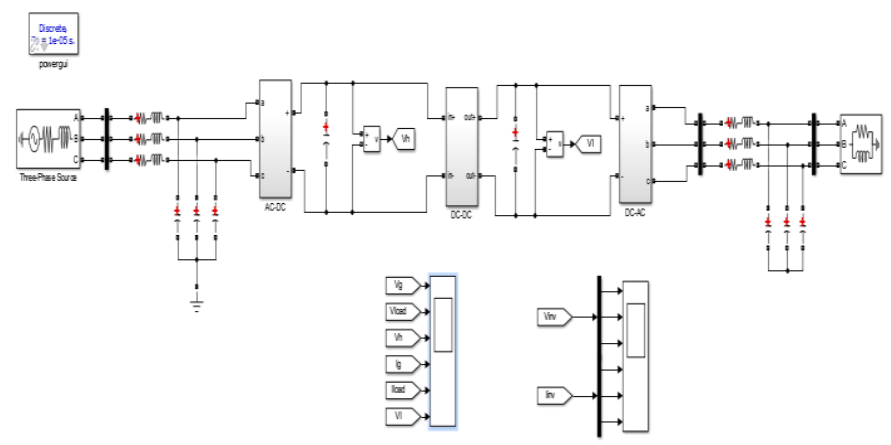

Fig.12. Simulation circuit diagram of three stage SST
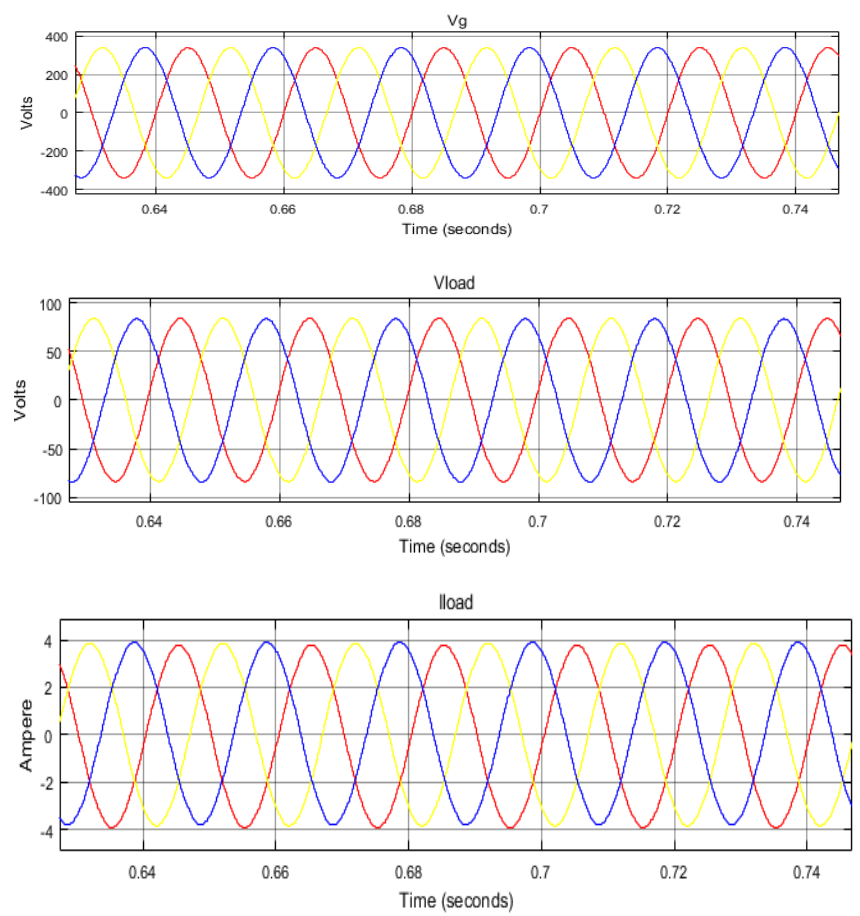

Fig.13. Simulation results of three stage SST

Table 4.2 Simulation Parameters for Single stage SST

\begin{tabular}{|l|l|}
\hline Input voltage & $230 \mathrm{~V}$ \\
\hline Output voltage & $120 \mathrm{~V}$ \\
\hline Duty ratio & 0.8 \\
\hline Switching frequency & $1 \mathrm{KHz}$ \\
\hline Array peak power & $1 \mathrm{KW}$ \\
\hline
\end{tabular}

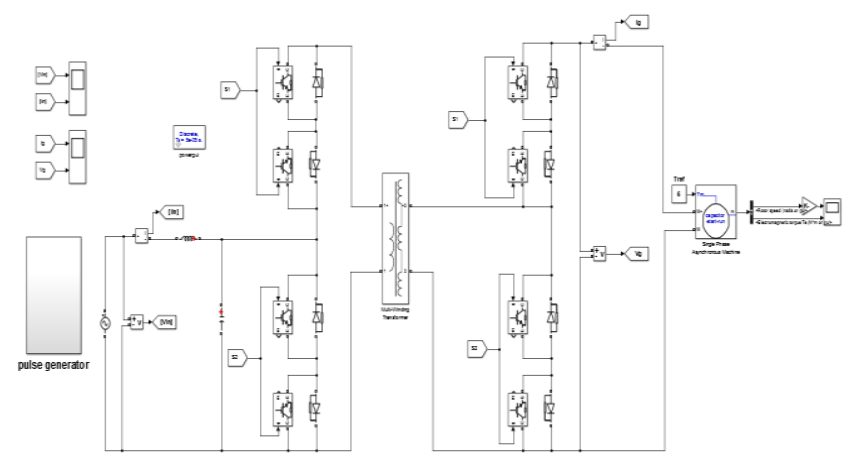

Fig.14. Simulation diagram of single stage SST

\section{INPUT VOLTAGE(Volts)}

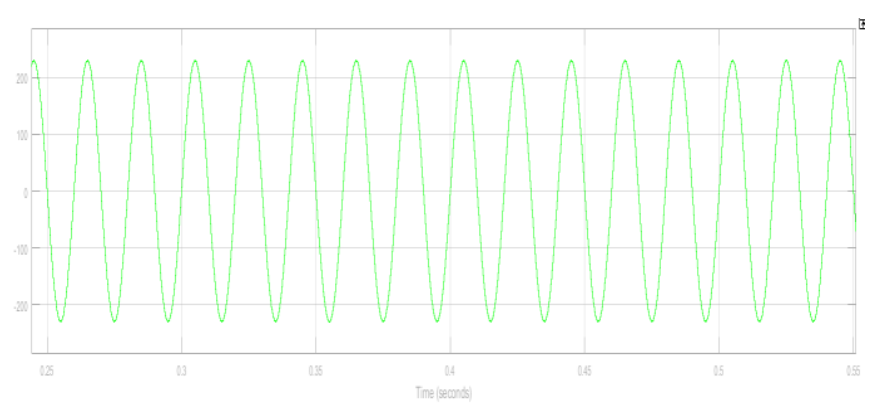

OUTPUT VOLTAGE(Volts)

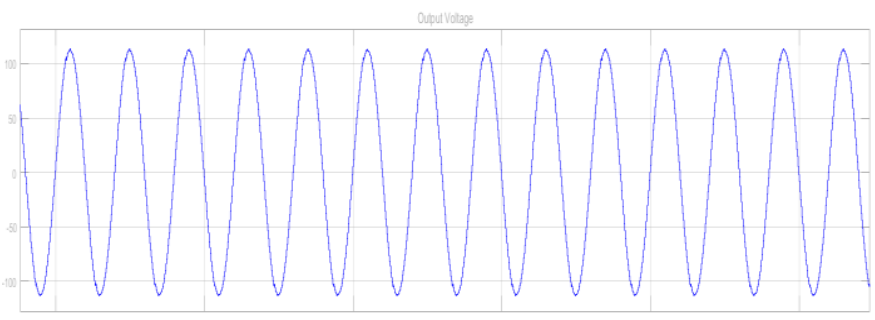

ELECTROMAGNETIC TORQUE(Nm)

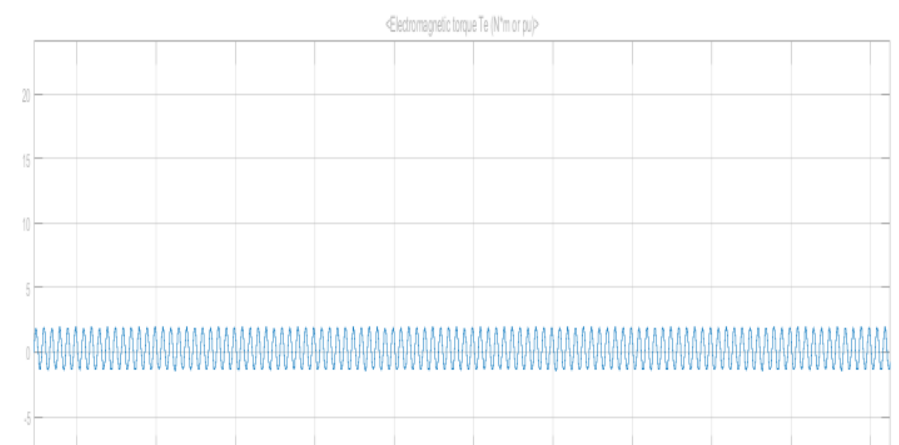

Fig.15. Simulation results of single stage SST

By comparing the single stage and three stage SST, from the simulation results, we can find that the output voltage is increased in single stage SST due to less voltage drop. In three stage SST, the number of stages are increased and thus voltage drop in each stage is also increased. Thus efficiency of a single 
stage SST is high. Also the voltage and current ripples are reduced. Also ripples in torque are also reduced. Thus, SSTs are used for high power density, high power quality and high efficiency.

\section{CONCLUSION}

It is concluded that the conventional transformer which was used widely in industrial applications so far has disadvantages like saturation of core for non linear load, no voltage sag and swell mitigation, poor voltage regulation, less efficiency, high losses, bulkiness, no compensation in power, no fault isolation, etc.. Majority of these problems are reduced or completely mitigated by solid state power electronic based intelligent transformer. Also it has the capability to work as energy router for smart grid energy internet. Thus the field of application of power electronic based solid state transformer is not limited up to distribution level but also having capacity to replace the conventional power transformer too in the near future. Also as we are in need of compact things having high power density, we will be using these transformers instead of conventional transformers. Thus SST has proven to be promising compensator with many advantages like high power quality, voltage control, fault isolation and reactive power compensation. There is no universal topology for all practical applications, so a separate topology is to be used for a particular application which creates huge problem to design.

\section{FUTURE SCOPE}

The SST topology with LVDC link provides an excellent and readily accessible integration point for renewable energy systems into the distribution grid. We can make use of a unidirectional converter when the load demand is larger than the renewable energy generation capability. The excess power could be fed back into the grid by using a bidirectional converter, when the peak generation capabilities exceed the load demand during certain periods.

Long distance power transmission from shore takes place by using DC SST interconnectors. Additionally for oil and gas applications in subsea frameworks, a less weight frame works gives points of interest like SST converters. Without floaters or any platforms, these devices give better flexibility than any conventional ones.

\section{ACKNOWLEDGEMENT:}

The successful completion of any task would be incomplete without mentioning the people who made it possible through their constant guidance and encouragement. I convey my thanks to Dr. Jegathesan V who is also my guide. I express my gratitude to his inspiration and guidance throughout my study. The interest he showed in my project was admirable and his encouragement motivated me to give my best. I take this opportunity to express my sincere thanks to Aiswarya K P who is my co supervisor. I thank her for his inspiration, cooperation and encouragement for pursuing research paper work.

\section{CONFLICT OF INTERERST:}

The authors declare that there is no conflict of interest and funding.

\section{REFERENCES}

[1]. E. Ronan, S. Sudhoff, S. Glover, and D. Galloway, "A power electronic based distribution transformer," Power Delivery, IEEE Transactions on, vol. 17, no. 2, pp. $537-543$, apr 2002.

[2]. Student paper submitted to IIT Delhi.

[3]. S. Falcones, X. Mao, and R. Ayyanar, "Topology comparison iifor solid state transformer implementation," in Power and Energy Society General Meeting, 2010 IEEE, 2010, pp. 1-8.

[4]. P. Drabek, Z. Peroutka, M. Pittermann, and M. Cedl, "New configuration of traction converter with medium-frequency transformer", Industrial Electronics, IEEE Transactions on, vol. 58, no. 11, pp. 5041-5048, Nov. 2011.

[5]. A. Shahani, K. Basu, and N. Mohan, "A power electronic transformer based onindirect matrix converter for pwm ac drive" in Power Electronics, Machines and Drives (PEMD 2012), 6th IET International Conference on, march 2012, pp. $1-6$.

[6]. H. Qin and J. Kimball, "Solid-state transformer architecture using ac-ac dual-active-bridge converter," Industrial Electronics, IEEE Transactions on, vol. 60, no. 9, pp. 3720-i3730, 2013

[7]. M.R. Banaei, E. Salary. "Mitigation of voltage sag, swell and power factor correction using solid-state transformer based matrix converter in output stage", Alexandria Engineering Journal, 2014.

[8]. X. She, A. Huang, and R. Burgos, "Review of solidstate transformer technologies and their application in power distribution systems," IEEE Journal of, vol. 1, no. 3, pp. 186-198, 2013.

[9]. M. D. Manjrekar, R. Kieferndorf, and G. Venkataramanan, "Power electronic transformers for utility applications," in Proc. IEEE Inst.Aeronaut. Sci. (IAS), 2000, pp. 2496-2502.

[10]. Yupeng Liu1 “ Control of single-stage AC-AC Solid State Transformer for Power Exchange Between Grids" IEEE 11th Conference on Industrial Electronics and Application 2016, pp.892-896.

[11]. Johann w. kolar, Jones E. Huber "Solid state transformers key design challenges, applicability and future concepts." Power Electronic Systems Laboratry.

[12]. D. Chen and J. Liu, "The unipolarity phase-shifted controlled voltage mode AC-AC converters with high frequency AC link," IEEE Trans. Power Electron., vol. 21, no. 4, pp. 899-905, Jul. 2006. 
[13]. G. R. Walker, P. C. Sernia, "Cascaded DC-DC converter connection of photovoltaic modules," IEEE Trans. Power. Electron., vol. 19, no. 4, pp. 11301139, July. 2004.

[14]. H. Krishnaswami, and V. Ramanarayanan, "Control of high-frequency AC link electronic transformer," in Proc. IEE Electric Power Applications, 6 May 2005, vol. 152, pp. 509-516.

[15]. M. Kang, P. Enjeti, and I. Pitel, "Analysis and design of electronic transformers for electric power distribution system," Power Electronics, IEEE Transactions on, vol. 14, no. 6, pp. 1133-1141, 1999.

[16]. Yupeng Liu1 “ Control of single-stage AC-AC Solid State Transformer for Power Exchange Between Grids" IEEE $11^{\text {th }}$ Conferenceon Industrial Electronics and Application 2016, pp.892-896

[17]. Subhadeep Paladhi, S Ashok, "Solid state transformer application in wind based DG system", 2015 IEEE International conference on Signal Processing, Informatics, Communication and Energy Systems (SPICES), 2015.

[18]. Alya Al-Hafri, Hamda, Amer Ghas, Qassim Nasir "Transformer-less based solid state transformer for intelligent power management", $20165^{\text {th }}$ International Conference on Electronic Devices, Systems and Applications (ICEDSA), 2016.

[19]. D.Wang, C. Mao, and J. Lu, "Operation and control mode of electronic power transformer," in Proc.
IEEE Sustainable Alternative Energy, 28-30 Sep. 2009, pp. 1-5.

[20]. VijayakrishnaSatyamsetti, Andreas Michealides, Antonis Hadjiantonis, "Forcastig on solid state transformer applications", 2017 International Conference on Intelligent Sustainable Systems (ICISS), 2017.

[21]. H. Keyhani, H. Toliyat, M. Todorovic, R. Lai, and R. Datta, "An isolated resonant ac-link three-phase acac converter using a single hf transformer," Industrial Electronics, IEEE Transactions, no. 99, pp.1-1, 2014.

[22]. Hengsi Qin Jonathan W. Kimball "Solid state transformer architecture using AC-AC Dual-active bridge converter" IEEE trans.on Industrial Electronics, Vol 6. No.9, PP-3720-3730.

[23]. C. Zhao, D. Dujic, A. Mester, et.al, "Power Electronic Traction Transformer-Medium Voltage Prototype," IEEE Transactions on Industrial Electronics, 2014, 61(7): 3257-3268.

[24]. S. Xu, A. Q. Huang, S. Lukic, and M. E. Baran, “On integration of solid state transformer with zonal DC microgrid," IEEE Trans. Smart Grid, vol. 3, no. 2, pp. 975-985, Jun. 2012.

[25]. Nicholas Parks, Sumit Dutta, Vivek Ramachandran, Kamalesh Hatua, Subhashish Battacharya, "Black start control of a solid state transformer for emergency power restoration", 2012 IEEE Energy Conversion Congress and Exposition (ECCE), 2012. 